\title{
Estimation of the transmission of foot-and-mouth disease virus from infected sheep to cattle
}

\author{
Carla Bravo de Rueda ${ }^{1,2}$, Mart CM de Jong ${ }^{2}$, Phaedra L Eblé ${ }^{1}$ and Aldo Dekker ${ }^{1 *}$
}

\begin{abstract}
The quantitative role of sheep in the transmission of foot-and-mouth disease virus (FMDV) is not well known. To estimate the role of sheep in the transmission of FMDV, a direct contact transmission experiment with 10 groups of animals each consisting of 2 infected lambs and 1 contact calf was performed. Secretions and excretions (oral swabs, blood, urine, faeces and probang samples) from all animals were tested for the presence of FMDV by virus isolation (VI) and/or RT-PCR. Serum was tested for the presence of antibodies against FMDV. To estimate FMDV transmission, the VI, RT-PCR and serology results were used. The partial reproduction ratio $\mathrm{R}_{0}{ }^{\mathrm{P}}$ i.e. the average number of new infections caused by one infected sheep introduced into a population of susceptible cattle, was estimated using either data of the whole infection chain of the experimental epidemics (the transient state method) or the final sizes of the experimental epidemics (the final size method). Using the transient state method, $\mathrm{R}_{0}{ }^{\mathrm{p}}$ was estimated as $1.0(95 \% \mathrm{Cl}$ 0.2 - 6.0) using virus isolation results and $1.4\left(95 \% \mathrm{Cl} 0.3\right.$ - 8.0) using RT-PCR results. Using the final size method, $\mathrm{R}_{0}{ }^{\mathrm{P}}$ was estimated as 0.9 ( $95 \% \mathrm{Cl} 0.2$ - 3.0). Finally, $R_{0}{ }^{p}$ was compared to the $R_{0}{ }^{\prime}$ s obtained in previous transmission studies with sheep or cattle only. This comparison showed that the infectivity of sheep is lower than that of cattle and that sheep and cattle are similarly susceptible to FMD. These results indicate that in a mixed population of sheep and cattle, sheep play a more limited role in the transmission of FMDV than cattle.
\end{abstract}

\section{Introduction}

Foot-and-mouth disease (FMD) is a contagious viral disease in cloven-hoofed animals caused by foot-andmouth disease virus (FMDV). Clinical signs of FMD in sheep are frequently mild or not apparent [1]. But while sheep may not manifest clear clinical signs of FMD, they can secrete and excrete considerable amounts of FMDV [2-4] and therefore may play a significant role in FMDV transmission. Transmission of FMDV between sheep [5-8] and between cattle [9-11] has been studied previously. Transmission of FMDV from sheep to cattle may have occurred during the 1994 type O epidemic in Greece [12], during the 1999 type O epidemics in Morocco [13] and during the 2001 type O epidemics in UK [14]. However, transmission of FMDV from sheep to cattle has not yet been quantified.

In epidemiology, the reproduction ratio $\left(R_{0}\right)$ is an important quantitative parameter of transmission. $R_{0}$ is defined as the average number of new infections

\footnotetext{
* Correspondence: aldo.dekker@wur.nl

${ }^{1}$ Central Veterinary Institute (CVI), Wageningen UR, P.O. Box 65, 8200

AB, Lelystad, The Netherlands

Full list of author information is available at the end of the article
}

caused by one typical infectious individual, during its entire infectious period, introduced into a population made up entirely of susceptible individuals [15]. Major outbreaks of FMDV can occur only if $R_{0}$ is above 1 . In the previously mentioned studies, $R_{0}$ was estimated within species i.e. intraspecies transmission either in sheep or in cattle. When different species are mixed, the $R_{0}$ for a mixed population of cattle and sheep not only depends on the occurrence of intraspecies (cattle-to-cattle and sheep-to-sheep) transmission but also on the occurrence of interspecies (sheep-to-cattle and cattle-to-sheep) transmission. To estimate $\mathrm{R}_{0}$ for a mixed population of cattle and sheep, all 4 ( 2 intraspecies and 2 interspecies) transmission parameters have to be known. The 2 interspecies transmission parameters will be called partial $R_{0}$ 's to emphasise that these parameters are strictly speaking not reproduction ratios. On the interspecies transmission of FMDV between sheep and cattle no quantitative information is available yet.

Moreover, with estimates for the intraspecies and interspecies (partial) $R_{0}$ 's, relative infectivity and susceptibility of sheep and cattle can be determined. Because for FMDV, relative infectivity and susceptibility have not extensively 
been quantified, modellers have had to rely on educated guesses about the relative infectivity and susceptibility of cattle, sheep and pigs herds [16]. Knowledge on relative infectivity and susceptibility of different species would improve modelling of FMDV transmission and more importantly could be used to implement tailored control measures in accordance to the animal species.

This study fills part of the gap on quantitative information on interspecies transmission of FMD. We estimated interspecies transmission of FMDV from infected sheep to contact cattle by estimating a partial $R_{0}\left(R_{0}^{p}\right)$ for sheep to cattle transmission. Further, comparison of our results to those obtained in intraspecific transmission studies allowed us to define the relative infectivity and susceptibility of sheep and cattle.

\section{Materials and methods}

\section{Experimental design}

Twenty conventionally reared lambs (crossbred TexelaarNoordhollander) aged between 6 and 7 months and 10 conventionally reared calves (pure- or crossbred (87\%) Holstein-Frisian) aged between 6 and 8 months were used in this study. The study was performed in 10 separate animal rooms within the biosecurity facilities of the Central Veterinary Institute (CVI, Lelystad, The Netherlands). Each animal room was between 9 and $11 \mathrm{~m}^{2}$ in size. In each animal room, 2 infected lambs and 1 contact calf were housed together for 31 days. The study received ethical approval from the animal experiment committee of the CVI in accordance with Dutch law.

On the day of infection (0 days post infection (dpi)), all the lambs were moved to a separate animal room and inoculated with FMDV. Eight hours after inoculation, the lambs were reunited with their original roommates. The lambs were inoculated with FMDV strain Asia-1 TUR/11/2000 by intranasal instillation. The virus was obtained from the World Reference Laboratory for Footand-Mouth Disease (Pirbright, United Kingdom); it was passaged once in cattle before its use. The inoculum contained $10^{5.8}$ plaque forming units $(\mathrm{pfu}) / \mathrm{mL}$ (tested on primary lamb kidney cells). Each lamb received $1.5 \mathrm{~mL}$ of inoculum per nostril.

\section{Sampling procedures}

During animal inspection and/or sampling, animal caretakers changed coveralls and gloves between animal rooms. All the animals were inspected daily for clinical signs of FMD. In these inspections, rectal temperature above $39.5{ }^{\circ} \mathrm{C}$ in calves and above $40{ }^{\circ} \mathrm{C}$ in lambs was considered fever [17], and the animals were checked for the presence of vesicles and/or lameness. Oral swab samples were collected daily from each animal from 0 dpi until the end of the experiment (31 dpi). They were collected and processed as described previously [11], with the exception that we used medium containing $2 \%$ foetal bovine serum. The oral swab samples were stored at $-70{ }^{\circ} \mathrm{C}$ until analysis by virus isolation (VI) and real time RT-PCR. Probang samples were collected from each animal at 29, 30 and $31 \mathrm{dpi}$. These were stored at $-70{ }^{\circ} \mathrm{C}$ until analysis by real time RT-PCR. Heparinized blood samples were collected daily from each animal from 0 dpi until $11 \mathrm{dpi}$. The heparinized blood samples were centrifuged at $2500 \mathrm{RPM}$ for $15 \mathrm{~min}$; plasma was stored at $-70{ }^{\circ} \mathrm{C}$ until analysis by VI. Samples for serum (clotted blood) were collected twice per week from $0 \mathrm{dpi}$ till the end of the experiment ( $31 \mathrm{dpi})$. Serum was stored at $-20{ }^{\circ} \mathrm{C}$ until serological analysis.

From the calves urine samples were collected daily during the first two weeks of the experiment and then twice per week until the end of the experiment. Urine samples were collected, as calves were stimulated to urinate spontaneously by rubbing the skin next to the vulva. In the laboratory, $800 \mu \mathrm{L}$ of urine was mixed with $100 \mu \mathrm{L}$ of foetal bovine serum and $100 \mu \mathrm{L}$ of antibiotics (1000 U/mL of penicillin, $1 \mathrm{mg} / \mathrm{mL}$ of streptomycin, $20 \mu \mathrm{g} / \mathrm{mL}$ of amphotericin B, $500 \mu \mathrm{g} / \mathrm{mL}$ of polymixin $\mathrm{B}$, and $10 \mathrm{mg} / \mathrm{mL}$ of kanamycin). Urine samples were stored at $-70{ }^{\circ} \mathrm{C}$ until analysis by VI. From both animal species, faeces samples were collected from the rectum daily during the first two weeks of the experiment and then twice per week until the end of the experiment. Faeces samples were processed as described previously [18] with the exception that the samples were centrifuged at $3000 \mathrm{RPM}$ for $15 \mathrm{~min}$. The supernatants were stored at $-70{ }^{\circ} \mathrm{C}$ until analysis by VI.

\section{Virus detection}

All oral swab, heparinised blood, urine, and faeces samples were tested for the presence of FMDV as described previously [11], using plaque titration on monolayers of secondary lamb kidney cells (VI, i.e. detection of infectious virus particles). In addition all oral swab and probang samples were tested for the presence of FMDV using real time RT-PCR because in these samples neutralising antibodies, that could influence the virus isolation results, were expected to be present. RNA isolation was performed using the Magna Pure LC total Nucleid Acid Isolation kit (03 038 505) in the MagNa Pure 96 system (Roche ${ }^{\circ}$, Mannheim, Germany). Isolated RNA was tested as described previously [19] using a LightCycler 480 Real-Time PCR System (Roche ${ }^{\circ}$ ) with the exception that we used a Quantifast Probe RT-PCR Kit (Qiagen', Venlo, The Netherlands).

\section{Serological analysis}

The serum samples were tested for the presence of antibodies against both non-structural and structural proteins of FMDV. To detect antibodies against non-structural 
proteins, a PrioCHECK FMDV NS ELISA (Prionics ${ }^{\oplus}$, Lelystad, The Netherlands) was performed in accordance to the manufacturers' instructions. To detect antibodies against structural proteins, a virus neutralisation test (VNT) was performed as described previously [20], using the FMDV isolate Asia-1 TUR/11/2000 and Baby Hamster Kidney cells (BHK-21). Samples were considered to be positive when the VNT titres were above $10^{0.6}$ (VNT cut-off).

\section{Estimation of transmission parameters Interspecies transmission rate}

To estimate the transmission rate parameter $\beta$, which is the average number of new infections in a fully susceptible population caused by one typical infectious individual per unit of time [21], i.e. in our case the number of cattle (in a population of only cattle) that will become infected from one infectious lamb per day, we used a generalized linear model (GLM) [22]. The GLM was based on a stochastic SIR model [23] (in which infection dynamics are described by the change in number of susceptible (S), infectious (I), recovered $(\mathrm{R})$ and total number $(\mathrm{N})$ of animals). The GLM uses the number of new cases (of cattle in this case) as dependent variable and the total number of cattle as binomial total. The analysis is done with a complementary log-log (cloglog) link function, a binomial error term, and an offset as explained below [24].

The expression for the GLM is:

$$
\operatorname{clog} \log \mathrm{E}\left(\mathrm{C}_{\mathrm{t}} / \mathrm{S}_{\mathrm{t}}\right)=\ln (\beta)+\ln \left(\mathrm{I}_{\mathrm{t}} \Delta_{\mathrm{t}} / \mathrm{N}_{\mathrm{t}}\right)
$$

where $\ln (\beta)$ is the regression coefficient and $\ln \left(\mathrm{I}_{t} \Delta_{t} / \mathrm{N}_{t}\right)$ is the offset variable.

$\mathrm{E}\left(\mathrm{C}_{\mathrm{t}} / \mathrm{S}_{\mathrm{t}}\right)=$ the expected number of cases $\left(\mathrm{C}_{\mathrm{t}}\right)$ during the interval $(t, t+\Delta t)$ divided by the number of susceptible individuals $\left(\mathrm{S}_{\mathrm{t}}\right)$ at the start of the time interval (i.e. at $\mathrm{t}$ ).

$\beta=$ the transmission rate parameter.

$I_{t}=$ the number of infectious animals at the start of time interval $(\mathrm{t})$.

$\Delta \mathrm{t}=$ the duration of the time interval.

$\mathrm{N}_{\mathrm{t}}=$ the total number of animals at the start of the time interval $(\mathrm{t})$.

Note that because of the experimental design i.e. with all sheep infectious and all susceptible animals being cattle, the estimated $\beta$ is an interspecies transmission rate parameter of sheep to cattle.

We assumed that the lambs were infectious from the first day until the last day FMDV was detected in their oral swab samples (by either VI or RT-PCR). Calves were considered infected if FMDV or antibodies against FMDV were detected in their samples. Because no virus was detected in 2 of the 4 contact calves that seroconverted, we assumed that both calves became infected 7 days before they scored positive in the VNT (which corresponded to the results from the calves that tested positive in VI and/or RT-PCR).

The data were analysed using the statistical program $\mathrm{R}$ [25]. The 95\% confidence intervals (CI) of the estimated interspecies $\beta$ were calculated using the standard error of the mean of $\log \beta$.

\section{Infectious period: $T$}

We calculated the infectious period $(\mathrm{T})$ based on the presence of virus in the oral swab samples from the individual lambs. Also for this purpose, both VI and RT-PCR results were used separately. The first moment at which an individual lamb tested positive in virus detection was considered as day 1 of its infectious period. The last day on which an individual lamb tested positive in virus detection (even if at one or more days in between no virus was detected), was considered as the last day of its infectious period.

Because some lambs still scored positive in virus detection at the end of the experiment, the mean duration of the infectious period $\mathrm{T}$ was calculated using a parametric (exponential) survival analysis [26]. To that end the time series of the lambs that scored positive in virus detection at the last day of the observational period were treated as censored data. The survival analysis was performed using the statistical program R [25] with the package "survival" [27]. The 95\% confidence intervals (CI) of the estimated infectious period $\mathrm{T}$ were calculated using the standard error of the mean of $\log \mathrm{T}$.

\section{Partial reproduction ratio: $R_{0}^{p}$}

The partial reproduction ratio $\mathrm{R}_{0}^{\mathrm{p}}$ i.e. the average number of new infections caused by one infectious sheep, during its entire infectious period, when introduced into a population of susceptible cattle, was estimated using two different methods.

\section{The transient state method}

The transient state method takes the time course of the epidemic process into account [21]. We estimated the $\mathrm{R}_{0}{ }^{\mathrm{p}}$ by multiplying interspecies $\beta$ with the mean infectious period T, both estimated using VI and RT-PCR results. The $95 \%$ confidence intervals (CI) of the estimated reproduction ratio were calculated using exp $(\log \beta+\log$ $\mathrm{T} \pm 1.96 \cdot \sqrt{ }(\operatorname{var} \log \beta+\operatorname{var} \log \mathrm{T})$ based on the assumption that the log transformed parameters follow a normal distribution and are independent.

\section{The final size method}

The final size method is based on the total number of infected calves at the end of the direct contact experiment, under the assumption that the epidemic process has ended before the experiment is stopped [21]. Even 
though some sheep (in contact to calves that did not become infected) were still shedding virus at the end of the experiment, we assumed that the epidemic process had ended at the end of the experiment. This assumption was based on the fact that FMDV transmission, leading to virus detection in the contact calves, occurred during the first week of the experiment (calf $\mathrm{nr} 5457$ and calf $\mathrm{nr}$ 5463) at the moment when virus titres in oral swabs of sheep were high.

In a one-to-one experimental transmission design, the maximum likelihood estimate (MLE) of $R_{0}\left(R_{M L E}\right)$ can be derived analytically $[21,28]$. Because we used a two-to-one experimental transmission design, we derived the maximum likelihood estimate of $R_{0}: R_{M L E}=\frac{3}{\sqrt{1-p}}-3$ where $p$ is the total number of infection events divided by the number of independent replications. In the Additional files 1 and 2 the derivation of $R_{M L E}$ is shown in more detail. The confidence intervals for $p$ were derived from the binomial distribution. Consequently the confidence intervals for the final size $\mathrm{R}_{0}^{\mathrm{p}}$ could be calculated.

Relative infectivities and susceptibilities of sheep and cattle The relative infectivities and susceptibilities of sheep and cattle were determined by comparing the final size $\mathrm{R}_{0}^{\mathrm{p}}$ estimate obtained in this interspecies transmission study with the final size $R_{0}$ estimates obtained in intraspecies transmission studies performed previously. The (intraspecies) final size $\mathrm{R}_{0}$ estimates used were: $R_{0 \text { sheep-to-sheep }}=1.1[5,6]$ and $R_{0 \text { cattle-to-cattle }}=\infty[9]$, 2.52 [10], 14 (Bravo de Rueda et al., unpublished observations). By comparing $\mathrm{R}_{0}{ }^{\mathrm{p}}$ sheep-to-cattle with $\mathrm{R}_{0}$ sheep-to-sheep, we could determine the relative susceptibility of sheep and cattle. By comparing $\mathrm{R}_{0}{ }^{\mathrm{p}}$ sheep-to-cattle with $\mathrm{R}_{0}$ cattle-to-cattle, we could determine the relative infectivity of sheep and cattle.

\section{Results}

\section{FMD clinical signs}

In total 15 of the 20 inoculated lambs developed clinical signs of FMD (fever, vesicles and/or lameness). In lambs, fever $(n=13)$ was most frequently observed followed by vesicle formation $(n=11)$ and lameness $(n=10)$ (Table 1$)$. Only one of the 10 contact calves (nr 5457) developed fever and had vesicles on the feet; the other 9 calves did not show clinical signs of FMD.

\section{VI and RT-PCR}

All the lambs tested positive for FMDV in oral swabs by VI. FMDV was first detected at 1-3 dpi. Higher levels of FMDV in oral swabs were detected in the first week after infection (Table 2). At the end of the experiment, oral swabs of 3 lambs (nr 5452, 5456 and 5458) still contained the virus. In total, 16 lambs tested positive by VI in their blood. Only 1 lamb (nr 5458) tested VI positive in its faecal sample. Only one calf (nr 5457) tested positive for FMDV in its oral swabs by VI (at 7-11 dpi). Virus was also isolated from blood and urine samples of this calf. No virus was isolated from faeces samples from any of the calves.

All the lambs tested positive for FMDV RNA in oral swabs by means of RT-PCR (Table 3). FMDV RNA in oral swabs was first detected at 1-2 dpi. At the end of the experiment, 8 lambs ( $\mathrm{nr} 5446$, 5447, 5452, 5455, 5456, 5458, 5461 and 5464) still tested positive for FMDV RNA in oral swabs. In total 9 lambs tested positive for FMDV RNA in their probang samples. Two of the 10 contact calves (nr 5457 and nr 5463) tested positive for FMDV RNA in oral swabs. Another contact calf (nr 5442) tested positive for FMDV RNA in one of its probang samples.

\section{Serological results}

Neutralising antibodies (by VNT) (Figure 1) were developed by all lambs, as were antibodies against non-structural proteins (by NS-ELISA) (Table 1). Neutralising antibodies were developed by four of the ten contact calves (Figure 1), these four calves also developed antibodies against nonstructural proteins (Table 1) (calves nr 5442, 5457, 5463 and 5466). Calf 5457 became VNT positive at $14 \mathrm{dpi} ; 7$ days after becoming positive in VI and RT-PCR. Calf 5463 became VNT positive at $17 \mathrm{dpi} 7$ days after becoming positive in RT-PCR. Calf 5442 became VNT positive at $10 \mathrm{dpi}$ and calf 5466 became VNT positive at $17 \mathrm{dpi}$. Figure 1 shows the averages of the VNT titres from the VNT positive lambs, the averages of the VNT titres from the VNT negative calves and the individual VNT titres from the 4 VNT positive contact calves.

\section{Estimation of transmission parameters}

FMDV transmission occurred in 4 of the 10 groups. Calves 5457 and 5463 were detected infectious at $7 \mathrm{dpi}$ and at 10 dpi respectively. Calves 5442 and 5466 did not test positive in any of the virus detection methods but they developed neutralizing antibodies at 10 and $17 \mathrm{dpi}$ respectively. For the estimation of the transmission parameters, these calves were assumed becoming infected at $3 \mathrm{dpi}$ and at $10 \mathrm{dpi}$ respectively, 7 days prior to the detection of neutralising antibodies. The interspecies transmission rate parameter $\beta$, the infectious period $T$ and the partial reproduction ratio $R_{0}{ }^{p}$ were calculated using the results given in Tables 2 and 3 .

Using the VI results, the interspecies $\beta$ was estimated at 0.037 per day (95\% CI: $0.014-0.076)$ and the infectious period $\mathrm{T}$ (of the sheep) was estimated at 28 days (95\% CI 19. - 42.). Using the RT-PCR results, the interspecies $\beta$ was estimated at 0.031 per day ( $95 \%$ CI: $0.012-0.065)$ and the infectious period $\mathrm{T}$ (of the sheep) was estimated at 46 days (95\% CI 28. - 73.). By using the transient state 
Table 1 Results of the virus isolation, RT-PCR, serology and clinical inspection.

\begin{tabular}{|c|c|c|c|c|c|c|c|c|c|c|c|c|}
\hline \multicolumn{3}{|c|}{ Animal } & \multicolumn{2}{|c|}{ Virus isolation } & \multicolumn{2}{|c|}{ RT-PCR } & \multicolumn{2}{|c|}{ Serology } & \multicolumn{3}{|c|}{ FMD clinical signs } & \multirow{2}{*}{$\begin{array}{l}\text { Contact } \\
\text { infection }\end{array}$} \\
\hline Room & Species & $\mathrm{Nr}$ & Oral swabs & Blood & Oral swabs & Probang & NS-ELISA & $\overline{\text { VNT }}$ & Fever $^{a}$ & Vesicles & $\overline{\text { Lameness }}$ & \\
\hline \multirow[t]{3}{*}{1} & Calf & 5439 & - & - & - & - & - & - & - & - & - & No \\
\hline & Lamb & 5440 & + & + & + & + & + & + & + & + & + & \\
\hline & Lamb & 5441 & + & + & + & - & + & + & + & + & + & \\
\hline \multirow[t]{3}{*}{2} & Calf & 5442 & - & - & - & + & + & + & - & - & - & Yes \\
\hline & Lamb & 5443 & + & + & + & - & + & + & + & - & - & \\
\hline & Lamb & 5444 & + & - & + & + & + & + & - & - & - & \\
\hline \multirow[t]{3}{*}{3} & Calf & 5445 & - & - & - & - & - & - & - & - & - & No \\
\hline & Lamb & 5446 & + & - & + & - & + & + & - & - & - & \\
\hline & Lamb & 5447 & + & - & + & - & + & + & - & - & - & \\
\hline \multirow[t]{3}{*}{4} & Calf & 5448 & - & - & - & - & - & - & - & - & - & No \\
\hline & Lamb & 5449 & + & + & + & + & + & + & + & + & - & \\
\hline & Lamb & 5450 & + & + & + & - & + & + & + & - & - & \\
\hline \multirow[t]{3}{*}{5} & Calf & 5451 & - & - & - & - & - & - & - & - & - & No \\
\hline & Lamb & 5452 & + & + & + & + & + & + & - & - & - & \\
\hline & Lamb & 5453 & + & + & + & + & + & + & - & + & - & \\
\hline \multirow[t]{3}{*}{6} & Calf & 5454 & - & - & - & - & - & - & - & - & - & No \\
\hline & Lamb & 5455 & + & + & + & - & + & + & + & + & + & \\
\hline & Lamb & 5456 & + & + & + & + & + & + & + & + & + & \\
\hline \multirow[t]{3}{*}{7} & Calf & 5457 & + & + & + & - & + & + & + & + & - & Yes \\
\hline & Lamb & 5458 & + & + & + & - & + & + & + & + & + & \\
\hline & Lamb & 5459 & + & + & + & - & + & + & - & + & + & \\
\hline \multirow[t]{3}{*}{8} & Calf & 5460 & - & - & - & - & - & - & - & - & - & No \\
\hline & Lamb & 5461 & + & + & + & - & + & + & + & - & + & \\
\hline & Lamb & 5462 & + & + & + & - & + & + & + & - & + & \\
\hline \multirow[t]{3}{*}{9} & Calf & 5463 & - & - & + & - & + & + & - & - & - & Yes \\
\hline & Lamb & 5464 & + & + & + & + & + & + & + & + & - & \\
\hline & Lamb & 5465 & + & - & + & + & + & + & - & - & - & \\
\hline \multirow[t]{3}{*}{10} & Calf & 5466 & - & - & - & - & + & + & - & - & - & Yes \\
\hline & Lamb & 5467 & + & + & + & - & + & + & + & + & + & \\
\hline & Lamb & 5468 & + & + & + & + & + & + & + & + & + & \\
\hline
\end{tabular}

$+/-$, positive /negative in one or more of the tested samples.

afever in sheep: body temperature above $40^{\circ} \mathrm{C}$; fever in cattle: body temperature above $39.5^{\circ} \mathrm{C}$.

method and the VI results, the $\mathrm{R}_{0}{ }^{\mathrm{p}}$ was estimated to be 1.0 (95\% CI: 0.20 - 6.0). By using the transient state method and the RT-PCR results, the $\mathrm{R}_{0}{ }^{\mathrm{p}}$ was estimated to be 1.4 (95\% CI: 0.30 - 8.0). By using the final size method, $\mathrm{R}_{0}{ }^{\mathrm{p}}$ was estimated to be 0.90 (95\% CI: 0.20 - 3.0). The estimated transmission parameters using the results from the VI and the RT-PCR analysis are shown in Table 4.

Relative infectivities and susceptibilities of sheep and cattle The estimated $R_{0}{ }^{p}$ sheep-to-cattle is very similar to the $R_{0}$ sheep-to-sheep estimated previously (final size $R_{0}=1.1$ ) in two intraspecies transmission studies with sheep $[5,6]$, indicating that cattle and sheep are similarly susceptible to FMD.

The estimated $\mathrm{R}_{0}{ }^{\mathrm{p}}$ sheep-to-cattle is lower than the $\mathrm{R}_{0}$ cattle-to-cattle estimated previously in three intraspecific transmission studies with cattle (final size $R_{0}=\infty$ [9], final size $R_{0}=2.52$ [10] and final size $R_{0}=14$ in Bravo de Rueda et al., unpublished observation), indicating that cattle are more infectious than sheep.

\section{Discussion}

The purpose of this study was to estimate transmission of FMDV from infected sheep to contact cattle and, together with results from previous studies, to identify differences 
Table 2 FMDV virus titres in oral swab, blood, urine and faeces samples.

\begin{tabular}{|c|c|c|c|c|c|c|c|c|c|c|c|c|c|c|c|c|c|c|c|c|c|c|c|c|c|c|c|c|c|c|c|c|c|}
\hline \multirow[b]{2}{*}{ Animal } & \multicolumn{33}{|c|}{ Days post infection } \\
\hline & $\mathrm{Nr}$ & 0 & 1 & 2 & 3 & 4 & 5 & 6 & 7 & 8 & 9 & 10 & 11 & 12 & 13 & 14 & 15 & 16 & 17 & 18 & 19 & 20 & 21 & 22 & 23 & 24 & 25 & 26 & 27 & 28 & 29 & 30 & 31 \\
\hline Calf & 5439 & $-^{a}$ & - & tox $^{\mathrm{b}}$ & - & - & - & - & - & - & - & - & N.A. ${ }^{c}$ & - & - & - & - & - & - & - & - & - & - & - & - & - & - & - & - & - & - & - & - \\
\hline Lamb & 5440 & - & $2.6^{d}$ & tox & $3.8 \mathrm{~N}^{\mathrm{d}}$ & 1.6 & - & 0.9 & - & - & - & 0.7 & N.A. & - & - & - & 1.1 & - & - & 1.7 & 1.1 & 0.7 & - & 1.0 & - & - & 1.2 & - & 1.4 & - & - & - & - \\
\hline Lamb & 5441 & - & 1.3 & tox & $2.1 \mathrm{~N}$ & 1.3 & 1.4 & - & - & - & - & - & N.A. & - & - & - & - & - & - & - & - & - & - & - & - & - & - & - & - & - & - & - & - \\
\hline Calf & 5442 & - & - & tox & $-* e$ & - & - & - & - & - & - & - & N.A. & - & - & - & - & - & - & - & - & - & - & - & - & - & - & - & - & - & - & - & - \\
\hline Lamb & 5443 & - & - & tox $N$ & $2.8 \mathrm{~N}$ & $-N$ & 1.0 & 0.4 & - & - & - & - & N.A. & - & - & - & - & - & - & - & - & 0.4 & - & - & - & 1.2 & - & 0.4 & - & - & - & - & - \\
\hline Lamb & 5444 & - & 2.2 & tox & - & 0.4 & 1.0 & 0.9 & - & - & - & 1.0 & N.A. & 1.5 & - & 0.4 & 1.8 & - & 1.5 & 2.1 & 1.2 & 0.9 & - & 1.1 & - & 1.7 & - & 1.0 & 0.4 & - & - & - & - \\
\hline Calf & 5445 & - & - & tox & - & - & - & - & - & - & - & - & N.A. & - & - & - & - & - & - & - & - & - & - & - & - & - & - & - & - & - & - & - & - \\
\hline Lamb & 5446 & - & 0.4 & tox & 4.0 & 3.3 & 2.2 & 0.4 & - & 0.4 & - & - & N.A. & - & - & 1.0 & 1.1 & - & 2.5 & N.A. & 0.4 & - & - & - & - & - & - & 1.3 & - & - & - & - & - \\
\hline Lamb & 5447 & - & 2.7 & tox & 0.4 & 2.4 & 2.4 & - & - & - & - & - & N.A. & - & - & 2.1 & 1.3 & 0.7 & 0.4 & - & 0.7 & 0.4 & - & - & - & - & - & 0.4 & - & - & - & - & - \\
\hline Calf & 5448 & - & - & tox & - & - & - & - & - & - & - & - & N.A. & - & - & - & - & - & - & - & - & - & - & - & - & - & - & - & - & - & - & - & - \\
\hline Lamb & 5449 & - & $2.1 \mathrm{~N}$ & tox $N$ & $4.2 \mathrm{~N}$ & - & 0.9 & - & - & - & - & - & N.A. & - & - & - & - & - & - & - & - & - & - & - & - & - & - & - & - & - & - & - & - \\
\hline Lamb & 5450 & - & 3.7 & tox $N$ & $2.3 \mathrm{~N}$ & 1.4 & 1.5 & - & - & - & - & - & N.A. & - & - & - & 1.7 & - & 1.2 & 0.4 & - & 1.7 & - & - & - & 2.1 & - & 1.0 & - & - & - & - & - \\
\hline Calf & 5451 & - & - & tox & - & - & - & - & - & - & - & - & N.A. & - & - & - & - & - & - & - & - & - & - & - & - & - & - & - & - & - & - & - & - \\
\hline Lamb & 5452 & - & $-N$ & tox $N$ & 4.0 & 1.6 & - & 0.4 & - & - & - & - & N.A. & - & - & - & - & - & 2.2 & 2.0 & 1.7 & 0.4 & 1.8 & 1.9 & - & - & 0.9 & 1.3 & 1.3 & 1.6 & - & - & 1.0 \\
\hline Lamb & 5453 & - & $0.4 \mathrm{~N}$ & tox $N$ & $2.3 \mathrm{~N}$ & 1.9 & 1.4 & 1.1 & - & - & - & 0.7 & N.A. & - & - & 1.9 & 1.5 & 0.7 & 0.4 & - & - & - & - & - & - & - & - & 1.5 & - & - & - & - & - \\
\hline Calf & 5454 & - & - & tox & - & - & - & - & - & - & - & - & N.A. & - & - & - & - & - & - & - & - & - & - & - & - & - & - & - & - & - & - & - & - \\
\hline Lamb & 5455 & - & - & tox & $0.7 \mathrm{~N}$ & $0.7 \mathrm{~N}$ & 1.9 & 0.4 & - & - & - & - & N.A. & - & - & 1.4 & 0.9 & 1.4 & 1.5 & 1.4 & - & - & - & 0.9 & - & - & - & - & 1.4 & - & - & 1.2 & - \\
\hline Lamb & 5456 & - & 1.6 & tox & $2.7 \mathrm{~N}$ & $2.1 \mathrm{~N}$ & 1.0 & 0.4 & - & - & - & - & N.A. & - & - & 1.0 & 0.4 & - & 0.9 & 1.4 & 1.5 & - & - & 0.4 & - & - & - & 0.9 & - & - & 1.7 & - & 0.7 \\
\hline Calf & 5457 & - & - & tox & - & - & - & - & $3.1 N^{*}$ & $3.4 \mathrm{~N}$ & $4.3 N^{f}$ & $4.3^{f}$ & N.A. ${ }^{f}$ & - & - & - & - & - & - & - & - & - & - & - & - & - & - & - & - & - & - & - & - \\
\hline Lamb & 5458 & - & 0.7 & tox & $3.9 \mathrm{~N}$ & 0.9 & 0.9 & 1.2 & - & - & -9 & & N.A. & - & - & 1.3 & 1.9 & 2.5 & 2.8 & 2.5 & 0.4 & 2.1 & 2.6 & 2.4 & 1.5 & 1.6 & - & 1.7 & - & 2.3 & - & 0.4 & 2.4 \\
\hline Lamb & 5459 & - & 1.6 & tox & $2.8 \mathrm{~N}$ & 2.2 & 0.4 & - & - & - & - & 2.3 & N.A. & - & 0.9 & 2.6 & - & 1.2 & 1.2 & 1.8 & 1.9 & - & 1.5 & 2.3 & - & 1.2 & 1.7 & 1.4 & - & 0.7 & - & 1.6 & - \\
\hline Calf & 5460 & - & - & tox & - & - & - & - & - & - & - & - & N.A. & - & - & - & - & - & - & - & - & - & - & - & - & - & - & - & - & - & - & - & - \\
\hline Lamb & 5461 & - & $0.4 \mathrm{~N}$ & tox $N$ & $2.7 \mathrm{~N}$ & 1.2 & 0.7 & - & - & - & - & - & N.A. & - & - & 0.4 & 1.4 & - & 0.9 & - & - & - & 1.2 & 1.7 & - & - & - & - & - & - & - & - & - \\
\hline Lamb & 5462 & - & $2.1 \mathrm{~N}$ & tox $N$ & $4.0 \mathrm{~N}$ & 1.7 & 1.9 & - & - & - & - & - & N.A. & - & - & - & - & - & - & 0.9 & - & - & - & 1.1 & - & - & - & - & - & 1.6 & - & - & - \\
\hline Calf & 5463 & - & - & - & - & - & - & - & - & - & - & $-*$ & N.A. & - & - & - & - & - & - & - & - & - & - & - & - & - & - & - & - & - & - & - & - \\
\hline Lamb & 5464 & - & 1.7 & 2.5 & 3.7 & $2.1 \mathrm{~N}$ & $0.9 \mathrm{~N}$ & - & - & - & - & - & N.A. & - & 1.7 & 1.5 & 1.2 & 2.6 & 0.9 & 1.2 & 2.3 & - & - & 1.8 & - & 1.2 & 2.2 & 2.5 & 1.7 & 0.4 & - & - & - \\
\hline Lamb & 5465 & - & - & 2.1 & - & 0.4 & 2.2 & - & - & - & 1.5 & - & N.A. & - & 2.1 & 1.1 & 1.3 & 2.7 & 1.2 & 2.0 & 1.2 & - & - & 1.2 & - & - & - & 0.7 & - & - & - & - & - \\
\hline
\end{tabular}


Table 2 FMDV virus titres in oral swab, blood, urine and faeces samples. (Continued)

\begin{tabular}{|c|c|c|c|c|c|c|c|c|c|c|c|c|c|c|c|c|c|c|c|c|c|c|c|c|c|c|c|c|c|c|c|}
\hline Calf & 5466 & $-\quad-$ & - & - & - & - & - & - & - & - & $-^{*}$ & N.A. & - & - & - & - & - & - & - & - & - & - & - & - & - & - & - & - & - & - & - \\
\hline Lamb & 5467 & $-\quad-N$ & $3.0 \mathrm{~N}$ & $2.7 \mathrm{~N}$ & 2.8 & 1.8 & - & - & - & - & - & N.A. & - & - & - & - & - & - & - & - & - & - & - & - & - & - & - & - & - & - & - \\
\hline Lamb & 5468 & $-4.0 \mathrm{~N}$ & $3.0 / \mathrm{N}$ & $-N$ & $1.4 \mathrm{~N}$ & 1.0 & - & - & - & - & - & N.A. & - & - & 1.0 & 0.9 & 0.4 & 1.2 & 0.4 & - & - & 1.8 & 2.0 & 2.1 & - & - & - & - & - & - & - \\
\hline
\end{tabular}

a oral swab sample that scored positive for FMDV by virus isolation (VI) (log10 pfu/mL); -: no virus was detected.

b tox: toxic oral swab sample, no Vl result available.

tox: toxic oral swab sample, no VI result available.

$\mathrm{N}$. .A.: results not-available for oral swab samples.
$\mathrm{V}=$ viraemia: blood sample that scored positive for FMDV by $\mathrm{V}$.

$f$ indicates the (estimated) day of infection of the conta

unine sample that scored positive for FMDV by VI.

gfaeces sample that scored positive for FMDV by VI. 


\begin{tabular}{|c|c|c|c|c|c|c|c|c|c|c|c|c|c|c|c|c|c|c|c|c|c|c|c|c|c|c|c|c|c|c|c|c|c|}
\hline \multirow[b]{2}{*}{ Animal } & \multicolumn{33}{|c|}{ Days post infection } \\
\hline & $\mathrm{Nr}$ & 0 & 1 & 2 & 3 & 4 & 5 & 6 & 7 & 8 & 9 & 10 & 11 & 12 & 13 & 14 & 15 & 16 & 17 & 18 & 19 & 20 & 21 & 22 & 23 & 24 & 25 & 26 & 27 & 28 & 29 & 30 & 31 \\
\hline$\overline{C a l f}$ & 5439 & $-{ }^{a}$ & - & - & - & - & - & - & - & - & - & - & N.A. ${ }^{b}$ & & & & & & & & & & - & - & - & - & - & - & - & - & - & - & - \\
\hline Lamb & 5440 & - & + & + & + & + & + & + & - & - & - & - & N.A. & - & + & + & + & + & + & + & + & + & + & + & + & + & + & + & + & - & - & + & - \\
\hline Lamb & 5441 & - & + & - & + & + & + & + & - & - & - & - & N.A. & - & - & - & - & 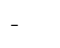 & 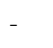 & - & - & - & - & - & - & - & - & - & - & - & - & - & - \\
\hline Calf & 5442 & - & - & - & - & - & - & - & - & - & - & - & N.A. & - & - & - & - & 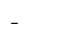 & - & - & - & - & - & - & - & - & - & - & - & - & - & - & - \\
\hline Lamb & 5443 & - & + & - & + & + & + & - & - & - & + & + & N.A. & - & + & - & + & - & - & - & - & + & - & - & + & + & - & + & - & - & - & + & - \\
\hline Lamb & 5444 & - & + & + & - & + & + & + & - & - & + & + & N.A. & + & - & + & + & - & + & + & + & + & + & + & + & + & - & + & + & + & - & - & - \\
\hline Calf & 5445 & - & - & - & - & - & - & - & - & - & - & - & N.A. & - & - & - & - & - & - & - & - & - & - & - & - & - & - & - & - & - & - & - & - \\
\hline Lamb & 5446 & - & + & - & + & + & + & + & + & + & + & + & N.A. & + & - & + & + & + & + & N.A. & + & + & + & + & + & + & - & + & + & + & - & - & + \\
\hline Lamb & 5447 & - & + & + & - & + & + & + & - & - & - & - & N.A. & - & - & + & + & + & + & + & + & + & + & - & + & - & - & - & - & - & - & - & + \\
\hline Calf & 5448 & - & - & - & - & - & - & - & - & - & - & - & N.A. & - & - & - & - & - & - & - & - & - & - & - & - & - & - & - & - & - & - & - & - \\
\hline Lamb & 5449 & - & + & + & + & + & + & + & - & - & - & - & N.A. & - & - & - & - & - & + & - & + & + & + & + & - & + & + & + & - & - & - & - & - \\
\hline Lamb & 5450 & - & + & - & + & + & + & + & + & - & - & - & N.A. & + & - & + & + & - & + & + & - & + & + & + & - & + & + & + & - & - & - & - & - \\
\hline Calf & 5451 & - & - & - & - & - & - & - & - & - & - & - & N.A. & - & - & - & - & - & - & - & - & - & - & - & - & - & - & - & - & - & - & - & - \\
\hline Lamb & 5452 & - & - & + & + & + & - & + & - & - & - & - & N.A. & - & + & + & + & + & + & + & + & + & + & + & + & + & + & + & + & + & - & + & + \\
\hline Lamb & 5453 & - & - & + & + & + & + & + & + & - & + & + & N.A. & + & + & + & + & + & + & + & - & + & - & + & + & + & + & + & + & + & - & + & - \\
\hline Calf & 5454 & - & - & - & - & - & - & - & - & - & - & - & N.A. & - & - & - & - & - & - & - & - & - & - & - & - & - & - & - & - & - & - & - & - \\
\hline Lamb & 5455 & - & + & + & + & + & + & - & - & - & - & - & N.A. & - & + & + & + & + & + & + & + & + & + & + & + & + & - & + & + & - & - & + & + \\
\hline Lamb & 5456 & - & + & + & + & + & + & + & + & - & + & + & N.A. & + & + & + & + & + & + & + & + & - & + & + & + & + & + & + & - & + & + & - & + \\
\hline Calf & 5457 & - & - & - & - & - & - & - & + & + & + & + & N.A. & + & + & - & - & - & - & - & - & - & - & - & - & - & - & - & - & - & - & - & - \\
\hline Lamb & 5458 & - & + & - & + & + & + & + & - & - & - & + & N.A. & - & + & + & + & + & + & + & + & + & + & + & + & + & - & + & - & + & - & + & + \\
\hline Lamb & 5459 & - & + & + & + & + & + & + & - & - & + & + & N.A. & + & + & + & + & + & + & + & + & + & + & + & + & + & + & + & - & + & - & + & - \\
\hline Calf & 5460 & - & - & - & - & - & - & - & - & - & - & - & N.A. & - & - & - & - & - & - & - & - & - & - & - & - & - & - & - & - & - & - & - & - \\
\hline Lamb & 5461 & - & + & - & + & + & + & - & - & - & - & - & N.A. & - & + & + & + & - & + & + & + & - & + & + & + & - & + & + & + & - & + & + & + \\
\hline Lamb & 5462 & - & + & + & + & + & + & - & - & - & - & - & N.A. & - & - & + & - & + & + & + & - & - & - & - & - & + & - & - & - & + & - & - & - \\
\hline Calf & 5463 & - & - & - & - & - & - & - & - & - & - & + & N.A. & + & - & - & - & - & - & - & - & - & - & - & - & - & - & - & - & - & - & - & - \\
\hline Lamb & 5464 & - & + & + & + & + & + & - & - & - & + & + & N.A. & + & + & + & + & + & + & + & + & + & + & + & + & + & + & + & + & + & + & + & + \\
\hline Lamb & 5465 & - & + & + & - & + & + & - & - & - & + & - & N.A. & + & + & + & + & + & + & + & + & + & - & + & + & + & - & - & - & - & - & + & - \\
\hline Calf & 5466 & - & - & - & - & - & - & - & - & - & - & - & N.A. & - & - & - & - & - & - & - & - & - & - & - & - & - & - & - & - & - & - & - & - \\
\hline Lamb & 5467 & - & + & + & + & + & + & - & - & - & - & - & N.A. & - & - & - & - & - & - & - & - & - & - & - & - & - & - & - & - & - & - & - & - \\
\hline Lamb & 5468 & - & + & + & + & + & + & + & + & + & + & + & N.A. & + & + & + & + & + & + & + & + & + & + & + & + & + & + & + & - & + & + & + & - \\
\hline
\end{tabular}

oral swab sample that scored positive for FMDV by RT-PCR; -: no virus was detected and +: virus detected. 


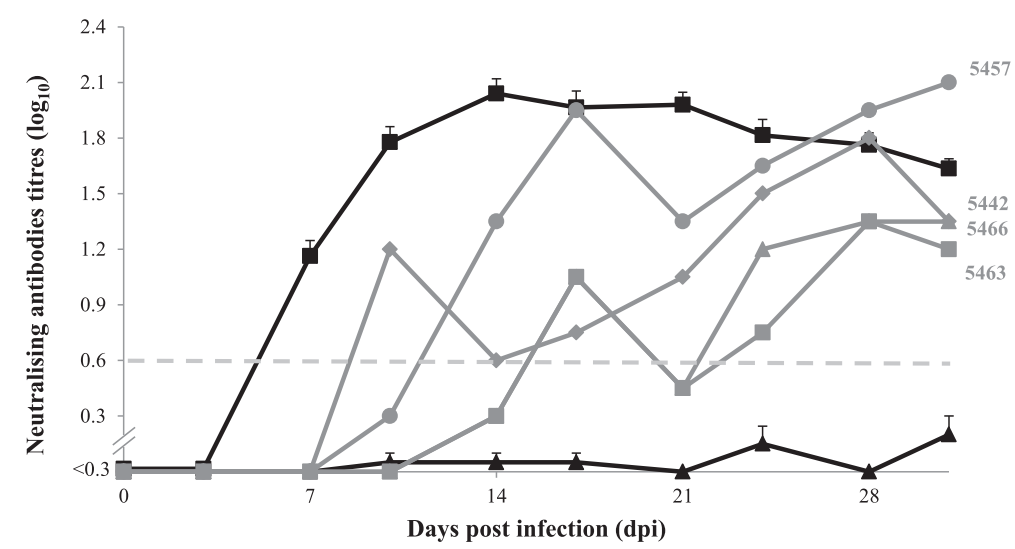

Figure 1 Results of VNT titres. The black line with solid boxes $\left(-\boldsymbol{C}\right.$ ) represents the average VNT titres $\left(\log _{10}\right)$ of the 20 inoculated sheep and the black line with solid triangles (- $(-)$ the average VNT titres of the 6 VNT negative contact calves. For the 4 VNT positive contact calves (in grey lines) the individual VNT titres are shown. The grey dashed line $(\square)$ indicates the VNT cut-off $\left(10^{0.6}\right)$. Error bars represent the standard error of the mean.

in either susceptibility to FMD or infectivity of FMD infected sheep and cattle. Our study shows that FMDV transmission from sheep to cattle occurs, but the estimated partial reproduction ratio $\left(\mathrm{R}_{0}^{\mathrm{P}}\right)$ indicates that the expected number of secondary cases in calves, caused by infected lambs, is relatively low. Moreover, the susceptibility of sheep to FMD seems to be similar to the susceptibility of cattle to FMD. This finding is supported by French et al. [29] who found overlapping distributions when analysing dose-response relationships in cattle and sheep exposed to FMDV in aerosols. The fact that cattle and sheep have a similar susceptibility to FMD and the fact that the transmission $\left(R_{0}\right)$ from cattle to cattle is higher than the transmission $\left(R_{0}{ }^{p}\right)$ from sheep to cattle, indicate that cattle are more infectious than sheep. Thus, cattle play the major role in the transmission of FMDV in a mixed population with sheep and cattle. These relative infectivities and susceptibilities are useful for modelling FMD spread such as for example in Backer et al. [16]. In their model they assumed that the susceptibility of cattle herds is twice the susceptibility of sheep herds. Our results can be used to update such FMD spread models, and more importantly, could be a reason to implement different control strategies for both animal species.

We estimated a partial reproduction ratio for sheep-tocattle transmission. This estimate alone does not reflect transmission for an entire mixed population consisting of sheep and cattle. In such a population, cattle-to-cattle, sheep-to-sheep, sheep-to-cattle and cattle-to-sheep transmission can take place. For the estimation of transmission in a mixed population, more information and/or other mathematical techniques are required [15]. Even though sheep play a more limited role in transmitting FMDV as compared to cattle, the reproduction ratio in a mixed population of sheep and cattle can still be larger than 1 , meaning that major outbreaks can occur. Probably, the $\mathrm{R}_{0}$ for a mixed population of cattle and sheep will be higher if a higher proportion of cattle are present.

Previously, we studied transmission of FMDV between cattle [9-11] and between sheep [6] using FMDV strain $\mathrm{O} / \mathrm{NET} / 2001$. However, different strains of FMDV might affect different species and might have different transmission characteristics. In more recent studies, we therefore used another serotype of FMDV to study transmission of FMDV. We chose FMDV Asia-1 because this serotype spread towards mainland Europe [30,31]. We observed transmission of FMDV Asia-1 between sheep [5] and between cattle (Bravo de Rueda et al., unpublished observation), and now studied transmission between sheep and cattle. The $R_{0}$ values obtained in the studies using serotype $\mathrm{O}$ and Asia-1 are not significantly different. Still, differences might exist for other serotypes.

Table 4 Estimated transmission parameters using the results from the Virus isolation (VI) and the RT-PCR analysis.

\begin{tabular}{|c|c|c|c|c|c|c|c|c|}
\hline & \multicolumn{2}{|c|}{ Transmission rate parameter (interspecies $\beta$ ) } & \multicolumn{2}{|c|}{ Infectious period $(\mathrm{T})$} & \multicolumn{4}{|c|}{ Partial reproduction ratio $\left(\mathrm{R}_{0}^{\mathrm{p}}\right)$} \\
\hline & \multirow[t]{2}{*}{$\beta\left(\right.$ day $\left.^{-1}\right)$} & \multirow[t]{2}{*}{$95 \% \mathrm{Cl}$} & \multirow[t]{2}{*}{$\mathrm{T}$ (days) } & \multirow[t]{2}{*}{$95 \% \mathrm{Cl}$} & \multicolumn{2}{|c|}{ Transient state method } & \multicolumn{2}{|c|}{ Final size method } \\
\hline & & & & & $\mathrm{R}_{0}^{\mathrm{p}}$ & $95 \% \mathrm{Cl}$ & $\mathrm{R}_{0}{ }^{\mathrm{p}}$ & $95 \% \mathrm{Cl}$ \\
\hline VI & 0.037 & $0.014-0.076$ & 28. & 19. - 42. & 1.0 & $0.20-6.0$ & & \\
\hline \multirow[t]{2}{*}{ RT-PCR } & 0.031 & $0.012-0.065$ & 46. & 28. - 73. & 1.4 & $0.30-8.0$ & & \\
\hline & & & & & & & 0.90 & $0.20-3.0$ \\
\hline
\end{tabular}


In this study, we investigated within pen transmission. The animals in this study were in close proximity. Extrapolation of experimental data to field conditions should always be done with care. However, the relative infectivity and susceptibility will not change under field conditions. In field conditions, the estimated $\mathrm{R}_{0}^{\mathrm{p}}$ will probably be lower because it is known that between-pen transmission is lower than within-pen transmission [32-34]. Additionally, between-herd transmission will most likely be even lower [35].

The relative low $\mathrm{R}_{0}^{\mathrm{p}}$ in the transmission of FMDV from sheep to cattle can have implications for control measures implemented during an outbreak, e.g. whether or not to use vaccination in sheep, given the fact that vaccination against FMD is very effective in cattle $[9,10]$. If all cattle were vaccinated and thus became less infectious, then vaccination of sheep would not have an additional contribution to FMD control, especially when other control measures are implemented e.g. movement restrictions.

The observed relatively low infectivity of sheep is remarkable if we take into consideration that the duration of the secretion and excretion of FMDV in sheep (specifically in oral swabs) is much longer than in cattle. The mean duration of secretion and excretion of FMDV in sheep, in this study, was 28 days (VI results from oral swab samples). A similarly long period was shown by Eblé et al. [5], who showed that sheep secrete and excrete FMDV for longer than 30 days. In contrast, calves infected with the same strain of FMDV, secrete and excrete FMDV for on average 5.0 days (VI results from oral swab samples in Bravo de Rueda et al., unpublished observation). It was already known that sheep are long- term secretors and excretors of FMDV [3,36]. Nevertheless the results reported here show that this long-term secretion and excretion of FMDV in sheep does not enhance transmission of the infection from sheep to cattle. In our study, transmission events took place mainly during the first week after infection. This is in accordance with what others have observed in sheep [5-8] and in cattle $[9,10]$.

In our study as well as in the above-mentioned studies, it was observed that FMDV is secreted and excreted in higher quantities during the first week post infection. Previous research showed that virus titres in upper respiratory tract samples from sheep are lower than those in cattle [4]. The ability of cattle to shed more virus than sheep could (partially) explain the observed difference in the infectivity of sheep and cattle. Moreover, in FMDV infected cattle, profuse salivation and nasal discharge are often observed [37]. Compared to cattle, salivation and nasal discharge after FMDV infection in sheep is less profuse i.e. sheep show less severe clinical signs $[1,38,39]$. Therefore it can be assumed that profuse secretion and excretion of the virus contributes to a higher contamination of the environment with FMDV. A recent analysis showed that FMDV transmission occurs for a large part through the environment (Bravo de Rueda et al., unpublished observations), and thus more new cases of FMD will take place if animals would shed more infected secretions and excretions.

We conclude that despite the ability of sheep to secrete and excrete FMDV for a relatively long period of time, sheep are less infectious than cattle. The observed differences in the relative susceptibility and infectivity of sheep and cattle could be a reason to implement different control strategies for both animal species.

\section{Additional files}

Additional file 1: Calculating reproduction ratio $\mathrm{R}_{0}$ in two-to-one transmission experiments. This additional file shows the analytical derivation of the maximum likelihood estimate (MLE) of $R_{0}\left(R_{M L E}\right)$ in a two-to-one experimental transmission design.

Additional file 2: The two-to-one transmission experiment is graphically represented as an SI (susceptible-infected) plane. This additional file is part of Additional file 1. This graph shows how a two-to-one transmission experiment can be represented using an infectious-susceptible plane. $\beta$ is the transmission rate parameter, $S_{t}$ is the number of susceptible animals, $l_{t}$ is the number of infectious animals, $N_{t}$ is the total number of animals and, a the recovery rate.

\section{Competing interests}

The authors declare that they have no competing interests.

\section{Authors' contributions}

CB participated in the design and coordination of the study, participated in the laboratory analysis, carried out the statistical analysis and drafted the manuscript. MJ participated in the design of the study, carried out the statistical analysis and drafted the manuscript. PE participated in the design and coordination of the study and helped to draft the manuscript. AD conceived the study, participated in the design and coordination of the study, carried out the statistical analysis and helped to draft the manuscript. All authors read and approved the final manuscript.

\section{Acknowledgements}

The authors would like to thank Mrs. F. van Hemert-Kluitenberg for her assistance with the handling of samples and laboratory assays. The research leading to these results have received funding from the European Community's Seventh Framework Programme (FP7/2007-2013) under grant agreement $n^{\circ}$ 226556 (FMD-DISCONVAC) and the Dutch Ministry of Economic affairs project (WOT-01-003-11)

\section{Author details}

${ }^{1}$ Central Veterinary Institute (CVI), Wageningen UR, P.O. Box 65, 8200 $A B$, Lelystad, The Netherlands. ${ }^{2}$ Department Quantitative Veterinary Epidemiology, Wageningen University, P.O. Box 338, 6700 AH Wageningen, The Netherlands.

Received: 17 December 2013 Accepted: 30 April 2014 Published: 27 May 2014

\section{References}

1. Kitching RP, Hughes GJ: Clinical variation in foot and mouth disease: sheep and goats. Rev Sci Tech 2002, 21:505-512

2. Burrows R: The persistence of foot-and-mouth disease virus in sheep. J Hyg (Lond) 1968, 66:633-640.

3. Donaldson Al, Sellers RF: Foot-and-mouth disease. In Diseases of Sheep. 3rd edition. Edited by Martin WB, Aitken ID. Oxford: Blackwell science; 2000:254-258.

4. de Bravo Rueda C, Dekker A, Eblé PL, de Jong MCM: Identification of factors associated with increased excretion of foot-and-mouth disease virus. Prev Vet Med 2014, 113:23-33. 
5. Eblé $P L$, Orsel $K$, Dekker A: FMDV infection in vaccinated and non-vaccinated sheep: transmission to contact animals and diagnostic aspects. In Session of the Research Group of the Standing Technical Committee of EUFMD; 29-31 October 2012. Jerez de la Frontera: FAO of the United Nations; 2012.

6. Orsel K, Dekker A, Bouma A, Stegeman JA, de Jong MCM: Quantification of foot and mouth disease virus excretion and transmission within groups of lambs with and without vaccination. Vaccine 2007, 25:2673-2679.

7. Cox SJ, Barnett PV, Dani P, Salt JS: Emergency vaccination of sheep against foot-and-mouth disease: protection against disease and reduction in contact transmission. Vaccine 1999, 17:1858-1868.

8. Parida S, Fleming L, Oh Y, Mahapatra M, Hamblin P, Gloster J, Paton DJ: Emergency vaccination of sheep against foot-and-mouth disease: significance and detection of subsequent sub-clinical infection. Vaccine 2008, 26:3469-3479.

9. Orsel K, de Jong MCM, Bouma A, Stegeman JA, Dekker A: The effect of vaccination on foot and mouth disease virus transmission among dairy cows. Vaccine 2007, 25:327-335.

10. Orsel K, Dekker A, Bouma A, Stegeman JA, de Jong MCM: Vaccination against foot and mouth disease reduces virus transmission in groups of calves. Vaccine 2005, 23:4887-4894.

11. Bouma A, Dekker A, de Jong MCM: No foot-and-mouth disease virus transmission between individually housed calves. Vet Microbio/ 2004 98:29-36.

12. Donaldson A: The role of sheep in the epidemiology of foot-and-mouth disease and proposasls for control and eradication in animal populations with a high density of sheep. In Session of the Research Group of the Standing Technical Committee of EUFMD 5-8 September 2000. Borovets: FAO of the United Nations; 2000.

13. Blanco E, Romero $\sqcup$, El Harrach M, Sanchez-Vizcaino JM: Serological evidence of FMD subclinical infection in sheep population during the 1999 epidemic in Morocco. Vet Microbiol 2002, 85:13-21.

14. Gibbens JC, Sharpe CE, Wilesmith JW, Mansley LM, Michalopoulou E, Ryan JB, Hudson M: Descriptive epidemiology of the 2001 foot-and-mouth disease epidemic in Great Britain: the first five months. Vet Rec 2001, 149:729-743.

15. Diekmann O, Heesterbeek JA, Metz JA: On the definition and the computation of the basic reproduction ratio $\mathrm{RO}$ in models for infectious diseases in heterogeneous populations. J Math Biol 1990, 28:365-382.

16. Backer JA, Hagenaars TJ, Nodelijk G, van Roermund HJ: Vaccination against foot-and-mouth disease I: epidemiological consequences. Prev Vet Med 2012, 107:27-40

17. Hajer R, Hendrikse J, Rutgers LE, Sloet van Oldruitenborgh-Oosterbaan MM, van der Weyden GC: Het klinisch onderzoek bij grote huisdieren. Bunge: Utrecht; 1985.

18. Weesendorp E, Stegeman A, Loeffen W: Dynamics of virus excretion via different routes in pigs experimentally infected with classical swine fever virus strains of high, moderate or low virulence. Vet Microbiol 2009, 133:9-22.

19. Moonen $\mathrm{P}$, Boonstra J, van der Honing $\mathrm{RH}$, Leendertse $\mathrm{CB}$, Jacobs $\mathrm{L}$, Dekker $\mathrm{A}$ Validation of a LightCycler-based reverse transcription polymerase chain reaction for the detection of foot-and-mouth disease virus. J Virol Methods 2003, 113:35-41.

20. Dekker A, Terpstra C: Prevalence of foot-and-mouth disease antibodies in dairy herds in The Netherlands, four years after vaccination. Res Vet Sci 1996, 61:89-91.

21. Velthuis AG, De Jong MCM, de Bree J, Nodelijk G, van Boven M: Quantification of transmission in one-to-one experiments. Epidemiol Infect 2002, 128:193-204.

22. McCullagh P, Nelder JA: Generalized Linear Models. 2nd edition. Boca Raton: Chapman and Hall/CRC; 1989.

23. Kermack WO, McKendrick AG: A contribution to the mathematical theory of epidemics. Proc R Soc Lond A 1927, 115:700-721.

24. Velthuis AG, De Jong MCM, Stockhofe N, Vermeulen TM, Kamp EM: Transmission of Actinobacillus pleuropneumoniae in pigs is characterized by variation in infectivity. Epidemiol Infect 2002, 129:203-214

25. R Development Core Team: R: A Language and Environment for Statistical Computing. Vienna: The R Foundation for Statistical Computing; 2012.

26. Klein JP, Moeschberger ML: Survival Analysis: Techniques for Censored and Truncated Data. New York: Springer; 2003.

27. Therneau TM: A Package for Survival Analysis in S, R package version 2.36-14.; 2012
28. Kroese AH, de Jong MCM: Design and analysis of transmission experiments. In Society for Veterinary Epidemiology and Preventive Medicine; 28-30 March. Edited by Menzies FD. Noordwijkerhout: Reid SWJ; 2001:21-36.

29. French NP, Kelly $L$, Jones $R$, Clancy D: Dose-response relationships for foot and mouth disease in cattle and sheep. Epidemiol Infect 2002, 128:325-332.

30. Lee KN, Oem JK, Park JH, Kim SM, Lee SY, Tserendorj S, Sodnomdarjaa R, Joo YS, Kim H: Evidence of recombination in a new isolate of foot-and-mouth disease virus serotype Asia 1. Virus Res 2009, 139:117-121.

31. Valarcher JF, Knowles NJ, Ferris NP, Paton DJ, Zakharov V, Sherbakov A, Shang YJ, Liu ZX, Liu X, Sanyal A, Hemadri D, Tosh C, Rasool TJ: Recent spread of FMD virus serotype Asia 1. Vet Rec 2005, 157:30.

32. Klinkenberg D, de Bree J, Laevens H, de Jong MCM: Within- and between-pen transmission of Classical Swine Fever Virus: a new method to estimate the basic reproduction ratio from transmission experiments. Epidemiol Infect 2002, 128:293-299.

33. van Roermund HJ, Eblé PL, de Jong MCM, Dekker A: No between-pen transmission of foot-and-mouth disease virus in vaccinated pigs. Vaccine 2010, 28:4452-4461.

34. Eblé PL, de Koeijer A, Bouma A, Stegeman A, Dekker A: Quantification of within- and between-pen transmission of Foot-and-Mouth disease virus in pigs. Vet Res 2006, 37:647-654.

35. Van Nes A, De Jong MCM, Buijtels JA, Verheijden JH: Implications derived from a mathematical model for eradication of pseudorabies virus. Prev Vet Med 1998, 33:39-58.

36. Geering WA: Foot and mouth disease in sheep. Aust Vet J 1967, 43:485-489

37. Thomson GR: Foot and mouth disease. In Infectious Diseases of Livestock with special reference to Southern Africa. Volume 2. 1st edition. Edited by Coetzer JAW, Thomson GR, Tustin RC. Capetown: Oxford University Press Southern Africa; 1994:825-851.

38. Gibson CF, Donaldson Al, Ferris NP: Response of sheep vaccinated with large doses of vaccine to challenge by airborne foot and mouth disease virus. Vaccine 1984, 2:157-161.

39. Hughes GJ, Mioulet V, Haydon DT, Kitching RP, Donaldson Al, Woolhouse ME Serial passage of foot-and-mouth disease virus in sheep reveals declining levels of viraemia over time. J Gen Virol 2002, 83:1907-1914.

doi:10.1186/1297-9716-45-58

Cite this article as: Bravo de Rueda et al.: Estimation of the transmission of foot-and-mouth disease virus from infected sheep to cattle. Veterinary Research 2014 45:58.

\section{Submit your next manuscript to BioMed Central and take full advantage of:}

- Convenient online submission

- Thorough peer review

- No space constraints or color figure charges

- Immediate publication on acceptance

- Inclusion in PubMed, CAS, Scopus and Google Scholar

- Research which is freely available for redistribution 